\title{
Packing density of cementitious materials: measurement and modelling
}

\author{
H. H. C. Wong and A. K. H. Kwan
}

The University of Hong Kong

Packing density has great effect on the performance of a concrete mix. However, little research has been carried out on the packing density of cementitious materials owing to the lack of an established measurement method. Herein, a new method, called the wet packing method, is presented. With this method, the packing densities of blended cementitious materials, consisting of ordinary Portland cement (OPC), pulverised fuel ash (PFA) and condensed silica fume (CSF), were measured. The results verified the theory that the packing density could be significantly increased by blending two or even three cementitious materials together. Comparison between the measured results and the predicted values by three existing packing models, together with some additional tests, revealed that in the presence of a third-generation superplasticiser, the packing density of CSF is dependent on the lime content. When the lime-containing OPC and PFA contents are low, the CSF particles would flocculate and pack rather loosely, but at higher OPC and PFA contents, or with lime added, the CSF would pack to a higher density. With the effect of lime accounted for, very good agreement between the measured results and the predictions by the packing models was achieved.

\section{Introduction}

The packing density of particles, which is defined as the ratio of the solid volume of the particles to the bulk volume occupied by the particles, is a fundamental parameter governing the properties of many materials made from particles, such as ceramics. ${ }^{1}$ In the field of powder technology, the packing density of particles has been a major theme of research. ${ }^{2}$ As a concrete mix is also composed largely of particles, its properties are greatly influenced by the packing density of the particles and hence research on the packing density of the constitutive materials can help to improve understanding of the behaviour of concrete.

Early in the 1960s, Powers ${ }^{3}$ studied the effects of the packing density of aggregate on the properties of fresh concrete. He argued for the excess paste theory, which states that concrete may be conceived as a mixture of aggregate and cement paste and it is the cement paste in excess of the amount needed to fill up the voids between the aggregate particles that disperses the parti-

Department of Civil Engineering, The University of Hong Kong, Hong Kong, China

(MACR-D-07-00004) Paper received 19 December 2006; last revised 19 June 2007; accepted 21 November 2007 cles and lubricates the concrete mix. Basically, a higher packing density of the aggregate would lead to a reduced paste demand (the amount needed to fill up the voids) and a larger amount of excess paste (the amount in excess of that needed to fill up the voids) for lubricating and improving the workability of the concrete mix. Apart from improving the workability, the higher packing density of the aggregate may also be utilised to reduce the paste volume for higher dimensional stability or to reduce the water/cementitious materials $(\mathrm{w} / \mathrm{cm})$ ratio for higher strength.

As the overall performance of a concrete could be enhanced by increasing the packing density of the aggregate, packing density optimisation of the aggregate has been a key issue in concrete mix design. Standard and fairly simple methods for measuring the packing density of aggregate are available in the existing codes. ${ }^{4,5}$ However, the packing density optimisation of aggregate is still largely conducted by means of a lengthy trial-and-error process. To reduce the labour and time required, some packing models developed in the field of powder technology have been successfully applied to predict theoretically the packing density of aggregate for packing density optimisation. ${ }^{6}$

Extending the excess paste theory and following the geometric similarity principle, it may be postulated that the packing density of the cementitious materials 
should have a similar effect as that of the aggregate: it is the water in excess of the amount needed to fill up the voids between the cementitious materials that disperses the particles and lubricates the cement paste. Hence, a higher packing density of the cementitious materials would lead to a reduced water demand (the amount needed to fill up the voids) and a larger amount of excess water (the amount in excess of that needed to fill up the voids) for lubricating and improving the flowability of the cement paste. Apart from improving the flowability, the higher packing density of the cementitious materials may also be utilised to reduce the paste volume for higher dimensional stability or to reduce the $\mathrm{w} / \mathrm{cm}$ ratio for higher strength.

It is generally believed that blending of ordinary Portland cement (OPC) with finer cementitious materials would increase the packing density. This has been demonstrated indirectly by the improved performance of the mortar or concrete produced when OPC is blended with a finer cementitious material. For example, Lange et al. ${ }^{7}$ have shown that by blending OPC with a finer blastfurnace-slag-based cement, the water demand of the cementitious materials could be reduced. $\mathrm{Kwan}^{8}$ has found that at a $\mathrm{w} / \mathrm{cm}$ ratio lower than $0 \cdot 28$, the addition of condensed silica fume, which has an average particle size smaller than $1.0 \mu \mathrm{m}$, could improve the workability of the concrete mix. Xie et al. ${ }^{9}$ have blended OPC with an ultra-fine pulverised fuel ash, which is finer than OPC, to produce a higherperformance concrete than possible with the use of only OPC. The improved performance so achieved has been attributed to the increase in packing density of the cementitious materials arising from the filling effect of the finer material. However, the actual packing densities of the cementitious materials have never been directly measured and the suggestion that blending of OPC with finer materials could improve packing density has remained a postulation which needs to be verified.

From the above studies, it is evident that the packing density optimisation of cementitious materials is also a key issue in concrete mix design. However, there are two major difficulties. First, there has been no established method for measuring the packing density of cementitious materials. The existing methods for measuring the packing density of aggregate, which are based on dry packing of the particles and thus may be called dry packing methods, are not applicable to any fine powders smaller than $100 \mu \mathrm{m}$ such as cementitious materials because the presence of inter-particle forces at micrometre size level would cause conglomeration of the particles leading to unreasonably low packing density results. ${ }^{2}$ Second, owing to lack of data from actual packing density measurement, it is not known whether the existing packing models are applicable also to cementitious materials. Without experimental and theoretical methods for estimating the packing density of cementitious materials, it is not possible to develop any systematic concrete mix design method based on packing density optimisation of the cementitious materials.

In the current paper, a new method of measuring the packing density of cementitious materials is presented. The method has been applied to measure the packing densities of blended cementitious materials containing different proportions of OPC, pulverised fuel ash (PFA) and condensed silica fume (CSF). The results so obtained served two purposes: $(a)$ to demonstrate how the packing density could be increased by double- or triple-blending different size cementitious materials together; and $(b)$ to check and verify the applicability of the existing packing models to cementitious materials. During the course of the research, it was found unexpectedly that the packing density of CSF in the presence of a third-generation superplasticiser is dependent on the lime content - that is, the content of $\mathrm{Ca}(\mathrm{OH})_{2}$ in the paste.

\section{Measuring packing density of cementitious materials}

There is still no standardised method for measuring the packing density of any fine powders smaller than $100 \mu \mathrm{m}$, especially cementitious materials. Different researchers used different methods yielding widely different results. Yu et al. ${ }^{10}$ measured the packing density of fine powders by pouring into a container and tapping under dry condition. This dry packing method is afflicted by conglomeration of the particles and its results are highly dependent on the degree of compaction applied. In the context of cementitious materials, it also has the problem of ignoring the effect of the mixing water. DeLarrard ${ }^{11}$ determined the packing density from the water demand of the cementitious materials taken as the water volume needed to produce a thick paste. This method is based on the assumption that the water volume needed to produce a thick paste is the same as the minimum voids volume of the cementitious materials. Dewar ${ }^{12}$ determined the packing density of cementitious materials as the solid concentration of the paste formed at standard consistence using a standard consistence test. ${ }^{13}$ This method is based on the assumption that the water volume of the paste formed at standard consistence is the same as the minimum voids volume of the cementitious materials. Both DeLarrard's method and Dewar's method ignore the presence of any air voids in the paste.

In this research, a new method, called the wet packing method, has been developed. As the name implies, the packing density of the cementitious materials is measured under wet condition with water and admixtures, if any, added. Unlike the previous methods, the new method directly measures the bulk densities of the paste formed at different $\mathrm{w} / \mathrm{cm}$ ratios. At a high $\mathrm{w} / \mathrm{cm}$ ratio, the paste is like a slurry with the cementitious materials dispersed as a suspension in water, whereas at 
a low $\mathrm{w} / \mathrm{cm}$ ratio, the paste contains a fair amount of air voids because the water added is insufficient to fill up the voids between the cementitious materials. With too much water added at high $\mathrm{w} / \mathrm{cm}$ ratio or some air entrapped at low $\mathrm{w} / \mathrm{cm}$ ratio, the solid concentration of the cementitious materials tends to be low at both high and low $\mathrm{w} / \mathrm{cm}$ ratios. In between, there exists an optimum $\mathrm{w} / \mathrm{cm}$ ratio at which the solid concentration attains a maximum. The maximum solid concentration is taken to be the packing density of the cementitious materials. By measuring the bulk densities of the paste, the presence of any entrapped air voids is implicitly taken into account.

The bulk density of a paste formed at a known w/cm ratio is measured by filling the paste into a cylindrical mould of known volume $V$ and measuring the mass of the paste $M$ inside the mould (the mould used is of $62 \mathrm{~mm}$ diameter $\times 60 \mathrm{~mm}$ height but any other mould of similar size may also be used). The solid volume $V_{\mathrm{c}}$ of the cementitious materials may be calculated from the following equation

$$
V_{\mathrm{c}}=\frac{M}{\rho_{\mathrm{w}} u_{\mathrm{w}}+\rho_{\alpha} R_{\alpha}+\rho_{\beta} R_{\beta}+\rho_{\gamma} R_{\gamma}}
$$

in which $\rho_{\mathrm{w}}$ is the density of water; $\rho_{\alpha}, \rho_{\beta}$ and $\rho_{\gamma}$ are the densities of the individual cementitious materials denoted by $\alpha, \beta$ and $\gamma ; u_{\mathrm{w}}$ is the $\mathrm{w} / \mathrm{cm}$ ratio by volume; and $R_{\alpha}, R_{\beta}$ and $R_{\gamma}$ are the volumetric ratios of $\alpha, \beta$ and $\gamma$ to the total cementitious materials. From this, the voids ratio $u$ and the solid concentration $\phi$ can be evaluated as

$$
\begin{gathered}
u=\left(V-V_{\mathrm{c}}\right) / V_{\mathrm{c}} \\
\phi=V_{\mathrm{c}} / V
\end{gathered}
$$

The values of $u$ and $\phi$ so obtained are dependent on the $\mathrm{w} / \mathrm{cm}$ ratio of the paste. Plotting the values of $u$ and $\phi$ against the $\mathrm{w} / \mathrm{cm}$ ratio (as will be illustrated later in Fig. 2), it can be seen that there exist a minimum value of $u$ and a maximum value of $\phi$. The minimum value of $u$ is the minimum voids ratio while the maximum value of $\phi$ is the packing density of the cementitious materials.

\section{Packing models}

In general, the packing density of a mix of monosize spherical particles varies from 0.60 for a non-ordered and unvibrated mix to 0.74 for an ordered and hexagonal close packed mix. The packing density of a binary mix of smaller particles and larger particles is dependent mainly on the volume fractions of the particles. When a small amount of smaller particles is added to the larger particles, the smaller particles would fill the voids between the larger particles and thereby increase the packing density (filling effect) while when a small amount of larger particles is added to the smaller parti- cles, the larger particles would occupy a solid volume within the bulk and porous volume of the smaller particles and thereby also increase the packing density (occupying effect). Hence, the blending together of different size particles could improve the packing density. However, if the two different size particles are not of distinct size, there would be particle interactions such that the smaller particles would loosen the packing of the larger particles in contact with each smaller particle (loosening effect) or the larger particles would act like walls and reduce the packing of the smaller particles in contact with each larger particle (wall effect).

To cater for multiple mix of more than two different size particles (also called multi-component mix or polydisperse mix), the above binary packing model has been extended into a variety of packing models. Most of them are based on the linear packing theory ${ }^{14}$ and may thus be classified as linear packing models. The linear packing theory stipulates that among the multiple components of different sizes there is at least one component that is fully packed and dominant (dominant in the sense that it divides the other components into smaller size and larger size components, which fill voids and occupy solid volumes respectively) and that the specific volume (ratio of bulk volume to solid volume) of the mix is the maximum of a series of linear functions of the volume fractions of the individual components (each linear function corresponds to one component assumed to be dominant). In the 1980s, the linear packing theory was improved to account for the particle interactions by Stovall et al. ${ }^{15}$ and $\mathrm{Yu}$ and Standish. ${ }^{16}$

Apart from the linear packing models, there are also packing models that deal with the multiple components by a stepwise approach of considering only two components at a time. ${ }^{12}$ One stepwise approach is to start with the finest component, mix it with the next coarser component, evaluate the specific volume of the mixture using a binary packing model, then, treating the mixture as a single component, mix it with another coarser component, and so on until all components have been included. Alternatively, the mixing sequence may also proceed from the coarsest component to the finest component. In theory, other mixing sequences may also be adopted.

In this research, three most advanced and popular packing models are employed to predict theoretically the packing density of the mixes of cementitious materials tested so as to investigate whether the test results agree with theoretical results and to find out whether the existing packing models are applicable to cementitious materials. They are the packing models developed by Yu et al. ${ }^{17}$ in 1996, by DeLarrard ${ }^{11}$ in 1999 and by Dewar $^{12}$ in 1999.

The model developed by Yu et al. (hereafter referred to as model A) is a linear packing model with the particle interactions allowed for. The interaction functions that allow for the loosening and wall effects were 
established by curve-fitting of test results. One major characteristic of this model is the incorporation of particle shape (in terms of sphericity) in the formulae for the interaction functions.

The model developed by DeLarrard (hereafter referred to as model B) is also a linear packing model with the particle interactions allowed for and the interaction functions established by curve-fitting of test results. Particle shape is not considered in the formulation. Instead, the degree of compaction applied is taken into account by incorporating a compaction index $K$ in the formulation.

The model developed by Dewar (hereafter referred to as model $\mathrm{C}$ ) is not a linear packing model. It adopts a stepwise approach of considering only two components at a time, starting with the finest component, mixing this component with the next coarser component to form a combined component and then mixing with another coarser component and so on. Particle interactions have been considered in terms of two interaction parameters $m$ and $Z$ established partly by geometric analysis and partly by calibration with test results.

The mathematical details of the above three packing models can be found in Refs 17, 11 and 12, respectively, and are thus not repeated here. For each packing model, a computer program in spreadsheet format has been written. These computer programs are easy to use (provided the user has basic knowledge of packing density modelling) and fast (computer time generally within a few minutes), and should be useful tools for packing density analysis and optimisation.

\section{Testing program}

A comprehensive testing program, involving the packing density measurement of 29 mixes of OPC + PFA + CSF at various mix proportions by the proposed wet packing method, has been launched. The 29 mixes were designed on a volumetric basis with the mix proportions of OPC, PFA and CSF expressed in terms of volume fractions (the volume fraction of each constitutive material is the ratio of the solid volume of the constitutive material to the total solid volume of all constitutive materials in the mix). Table 1 presents the details of the mix proportions of the mixes tested. It should be noted that each mix is given a mix No. and the 29 mixes may be divided into three categories: nonblended mixes (mix No. 1 to 3 for pure OPC, pure PFA and pure CSF), double-blended mixes (mix No. 4 to 8 for OPC + PFA, mix No. 9 to 13 for OPC + CSF and mix No. 14 to 18 for PFA + CSF) and triple-blended mixes (mix No. 19 to 29 for OPC + PFA + CSF).

The OPC, PFA and CSF employed were all commonly used materials obtained from the market. They had been tested to comply with BS EN 197, ${ }^{18}$ BS 3892: Part $1^{19}$ and ASTM $\mathrm{C} 1240-05,{ }^{20}$ respectively. Using
Table 1. Mix proportions of the mixes of cementitious materials tested

\begin{tabular}{|c|c|c|c|}
\hline \multirow[t]{2}{*}{ Mix No. } & \multicolumn{3}{|c|}{ Mix proportions: $\%$ by volume } \\
\hline & $\mathrm{OPC}$ & PFA & CSF \\
\hline 1 & 100 & 0 & 0 \\
\hline 2 & 0 & 100 & 0 \\
\hline 3 & 0 & 0 & 100 \\
\hline 4 & 85 & 15 & 0 \\
\hline 5 & 70 & 30 & 0 \\
\hline 6 & 55 & 45 & 0 \\
\hline 7 & 40 & 60 & 0 \\
\hline 8 & 25 & 75 & 0 \\
\hline 9 & 85 & 0 & 15 \\
\hline 10 & 70 & 0 & 30 \\
\hline 11 & 55 & 0 & 45 \\
\hline 12 & 40 & 0 & 60 \\
\hline 13 & 25 & 0 & 75 \\
\hline 14 & 0 & 85 & 15 \\
\hline 15 & 0 & 70 & 30 \\
\hline 16 & 0 & 55 & 45 \\
\hline 17 & 0 & 40 & 60 \\
\hline 18 & 0 & 25 & 75 \\
\hline 19 & 70 & 15 & 15 \\
\hline 20 & 55 & 30 & 15 \\
\hline 21 & 40 & 45 & 15 \\
\hline 22 & 25 & 60 & 15 \\
\hline 23 & 55 & 15 & 30 \\
\hline 24 & 40 & 30 & 30 \\
\hline 25 & 25 & 45 & 30 \\
\hline 26 & 40 & 15 & 45 \\
\hline 27 & 25 & 30 & 45 \\
\hline 28 & 10 & 45 & 45 \\
\hline 29 & 25 & 15 & 60 \\
\hline
\end{tabular}

the method given in BS 812: Part $2,{ }^{4}$ their solid densities had been measured to be 3110, 2329 and $2202 \mathrm{~kg} /$ $\mathrm{m}^{3}$, respectively. On the other hand, their particle size distributions are as shown in Fig. 1. For the OPC and PFA, the particle size distributions were obtained by laser diffraction measurement while for the CSF, the particle size distribution was obtained from the supplier. Both the PFA and CSF were basically spherical in shape and are thus assumed to have a sphericity of 1.000. The OPC was angular in shape. Its specific surface area had been measured in accordance with BS 4359: Part $2^{21}$ as $317 \mathrm{~m}^{2} / \mathrm{kg}$ whereas the specific surface area calculated from the particle size distribution with the particles assumed to be spherical was found to be $251 \mathrm{~m}^{2} / \mathrm{kg}$. From these two values, the sphericity of the OPC was determined, as stipulated by $\mathrm{Yu}$ et al., ${ }^{17}$ as $251 / 317=0 \cdot 792$.

During mixing of the cementitious materials with water to form a paste for testing, a superplasticiser (SP) was added to each mix. The SP used was a thirdgeneration SP based on a cross-linked polycarboxylate ether polymer. It has a solid mass content of $20 \%$ and a relative density of $1 \cdot 03$. According to the supplier, the normal dosage of the SP, measured in terms of liquid 


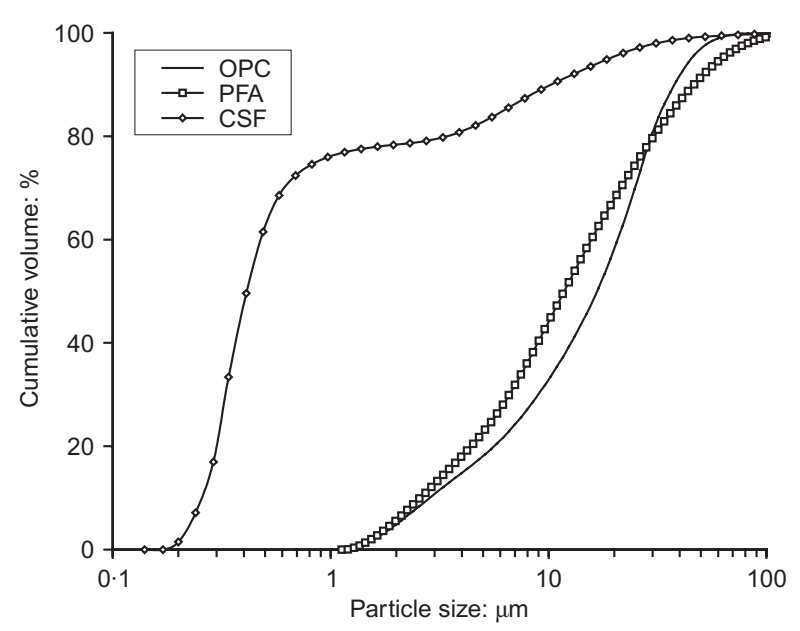

Fig. 1. Particle size distributions of the OPC, PFA and CSF

mass, should be $0 \cdot 5-3 \cdot 0 \%$ by mass of the cement. As the different cementitious materials have different densities and it is the solid volume rather than the mass that is more important, the SP dosage is expressed herein in terms of the liquid mass of SP per unit solid volume of the cementitious materials. The dosage of SP used in each mix was $93.3 \mathrm{~kg} / \mathrm{m}^{3}$ (same as the upper limit of normal dosage recommended by the supplier).

\section{Results and discussions}

\section{Wet packing behaviour of cementitious materials}

The wet packing behaviour of the cementitious materials may be depicted by plotting the voids ratio and the solid concentration of the paste formed against the $\mathrm{w} / \mathrm{cm}$ ratio by volume, as illustrated in Fig. 2 for the case of pure OPC. In the voids ratio/solid concentration diagram, an equality line of $u=\mathrm{w} / \mathrm{cm}$ ratio is also drawn to compare the voids ratio with the $w / \mathrm{cm}$ ratio

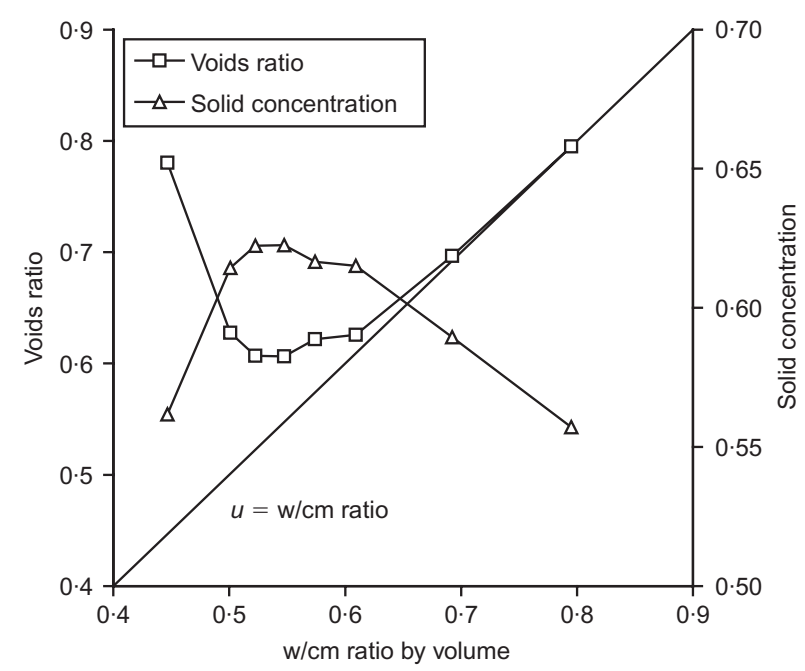

Fig. 2. Voids ratio/solid concentration diagram of pure OPC (note that all $\mathrm{w} / \mathrm{cm}$ ratios referred to herein are by volume and that the $\mathrm{w} / \mathrm{cm}$ ratio by volume is the same as the water ratio - that is, the ratio of volume of water to volume of solid).

From Fig. 2 it can be seen that for the case of pure $\mathrm{OPC}$, at a $\mathrm{w} / \mathrm{cm}$ ratio of $0 \cdot 8$, the voids ratio $u$ was very close to the $\mathrm{w} / \mathrm{cm}$ ratio, indicating that the voids were completely filled with water. Upon reduction of the w/ $\mathrm{cm}$ ratio to lower than $0 \cdot 7$, the voids ratio became slightly higher than the $\mathrm{w} / \mathrm{cm}$ ratio, revealing that the voids were only partly filled with water and there was a small amount of air in the voids (note that the difference between the voids ratio and the $\mathrm{w} / \mathrm{cm}$ ratio is actually the air ratio - that is, the ratio of volume of air to volume of solid). As the $\mathrm{w} / \mathrm{cm}$ ratio was reduced to lower than $0 \cdot 6$, the voids ratio became significantly higher than the $\mathrm{w} / \mathrm{cm}$ ratio. Eventually at a $\mathrm{w} / \mathrm{cm}$ ratio of 0.525 , the voids ratio reached a minimum value of 0.607 and the solid concentration reached a maximum value of 0.622 . At any $w / \mathrm{cm}$ ratio lower than 0.525 , the water added was not enough to produce a paste and therefore a large amount of air was entrapped in the mixture, leading to an increase in voids ratio and a decrease in solid concentration.

All the other mixes of cementitious materials tested were found to exhibit similar wet packing behaviour, as depicted in Fig. 2. In other words, for each mix tested, as the $\mathrm{w} / \mathrm{cm}$ ratio decreased from a relatively high value of about 1.0 to a relatively low value, the voids ratio decreased to a certain minimum value and then started increasing whereas the solid concentration increased to a certain maximum value and then started decreasing. From these test results, the packing density of each mix was obtained as the maximum solid concentration of the mix.

\section{Measured packing densities}

The measured packing densities of the non-blended cementitious materials are tabulated in Table 2 while the measured packing densities of the blended cementitious materials are tabulated in the second column of Table 3.

From Table 2, it is evident that the packing density of the OPC was slightly lower than that of the PFA. Since the OPC and PFA have similar particle size distributions, the difference in packing density could not have been caused by any significant difference in particle size. On the other hand, as the OPC particles

Table 2. Measured packing densities of pure cementitious materials

\begin{tabular}{l|c|c}
\hline Mix No. & Cementitious material & Measured packing density \\
\hline 1 & OPC & 0.622 \\
2 & PFA & 0.646 \\
3 & CSF & 0.397 \\
\hline
\end{tabular}


Table 3. Comparison between measured results and predictions by packing models

\begin{tabular}{|c|c|c|c|c|c|c|c|}
\hline \multirow[t]{2}{*}{ Mix No. } & \multirow{2}{*}{$\begin{array}{c}\text { Measured } \\
\text { packing density }\end{array}$} & \multicolumn{2}{|c|}{ Model A } & \multicolumn{2}{|c|}{ Model B } & \multicolumn{2}{|c|}{ Model C } \\
\hline & & $\begin{array}{c}\text { Predicted } \\
\text { packing density }\end{array}$ & Difference: \% & $\begin{array}{c}\text { Predicted } \\
\text { packing density }\end{array}$ & Difference: \% & $\begin{array}{c}\text { Predicted } \\
\text { packing density }\end{array}$ & Difference: $\%$ \\
\hline 4 & 0.637 & 0.628 & -1.4 & 0.627 & $-1 \cdot 6$ & 0.626 & -1.7 \\
\hline 5 & 0.641 & 0.633 & $-1 \cdot 2$ & 0.632 & $-1 \cdot 4$ & 0.631 & $-1 \cdot 6$ \\
\hline 6 & 0.644 & 0.637 & $-1 \cdot 1$ & 0.636 & $-1 \cdot 2$ & 0.635 & $-1 \cdot 4$ \\
\hline 7 & 0.643 & 0.640 & -0.5 & 0.640 & -0.5 & 0.639 & -0.6 \\
\hline 8 & 0.645 & 0.643 & $-0 \cdot 3$ & 0.643 & $-0 \cdot 3$ & 0.643 & $-0 \cdot 3$ \\
\hline 9 & 0.703 & 0.688 & $-2 \cdot 1$ & 0.661 & $-6 \cdot 0$ & 0.663 & $-5 \cdot 7$ \\
\hline 10 & 0.726 & 0.659 & $-9 \cdot 2$ & 0.661 & $-9 \cdot 0$ & 0.635 & $-12 \cdot 5$ \\
\hline 11 & 0.671 & 0.577 & $-14 \cdot 0$ & 0.579 & $-13 \cdot 7$ & 0.578 & $-13 \cdot 9$ \\
\hline 12 & 0.645 & $0 \cdot 514$ & $-20 \cdot 3$ & 0.515 & $-20 \cdot 2$ & 0.519 & $-19 \cdot 5$ \\
\hline 13 & 0.590 & $0 \cdot 463$ & $-21 \cdot 5$ & 0.463 & $-21 \cdot 5$ & 0.465 & $-21 \cdot 2$ \\
\hline 14 & 0.748 & 0.707 & $-5 \cdot 5$ & 0.674 & $-9 \cdot 9$ & 0.673 & $-10 \cdot 0$ \\
\hline 15 & 0.745 & 0.658 & $-11 \cdot 7$ & 0.661 & $-11 \cdot 3$ & 0.635 & $-14 \cdot 8$ \\
\hline 16 & 0.689 & 0.577 & $-16 \cdot 3$ & 0.578 & $-16 \cdot 1$ & 0.577 & $-16 \cdot 3$ \\
\hline 17 & 0.575 & 0.513 & $-10 \cdot 8$ & 0.514 & $-10 \cdot 6$ & $0 \cdot 518$ & -9.9 \\
\hline 18 & 0.410 & 0.463 & $+12 \cdot 9$ & 0.463 & $+12 \cdot 9$ & 0.465 & +13.4 \\
\hline 19 & $0 \cdot 718$ & 0.694 & $-3 \cdot 3$ & 0.665 & $-7 \cdot 4$ & 0.649 & $-9 \cdot 6$ \\
\hline 20 & 0.731 & 0.698 & $-4 \cdot 5$ & 0.669 & $-8 \cdot 5$ & 0.658 & $-10 \cdot 0$ \\
\hline 21 & 0.730 & 0.702 & $-3 \cdot 8$ & 0.671 & $-8 \cdot 1$ & 0.669 & -8.4 \\
\hline 22 & 0.742 & 0.704 & $-5 \cdot 1$ & 0.673 & $-9 \cdot 3$ & 0.675 & $-9 \cdot 0$ \\
\hline 23 & 0.736 & 0.659 & $-10 \cdot 5$ & 0.661 & $-10 \cdot 2$ & 0.623 & $-15 \cdot 4$ \\
\hline 24 & 0.735 & 0.658 & $-10 \cdot 5$ & 0.661 & $-10 \cdot 1$ & 0.625 & $-15 \cdot 0$ \\
\hline 25 & 0.752 & 0.658 & $-12 \cdot 5$ & 0.661 & $-12 \cdot 1$ & 0.634 & $-15 \cdot 7$ \\
\hline 26 & 0.665 & 0.577 & $-13 \cdot 2$ & 0.579 & $-12 \cdot 9$ & 0.574 & $-13 \cdot 7$ \\
\hline 27 & 0.691 & 0.577 & $-16 \cdot 5$ & 0.579 & $-16 \cdot 2$ & 0.575 & $-16 \cdot 8$ \\
\hline 28 & 0.700 & 0.577 & $-17 \cdot 6$ & 0.579 & $-17 \cdot 3$ & 0.576 & $-17 \cdot 7$ \\
\hline 29 & 0.639 & 0.514 & $-19 \cdot 6$ & $0 \cdot 515$ & $-19 \cdot 4$ & 0.516 & $-19 \cdot 2$ \\
\hline
\end{tabular}

were angular in shape whereas the PFA particles were spherical in shape, the difference in packing density was more likely attributable to the difference in particle shape (angular particles generally pack to a lower density than spherical particles ${ }^{22}$ ).

For the CSF, the measured packing density was found to be surprisingly low. One possible cause was the surface interaction between the SP and the CSF particles. The SP used was a third-generation SP. Unlike first- and second-generation SPs, a third-generation SP is a comb-type SP capable of dispersing OPC particles not only by electrostatic repulsion but also by steric repulsion derived from the grafted polyethylene oxide (PEO) side chains of the SP molecules. ${ }^{23}$ However, it may not have the same effectiveness in the dispersion of CSF particles. When CSF is mixed with water, the amorphous silica $\left(\mathrm{SiO}_{2}\right)$ of the CSF undergoes hydrolysis, resulting in the formation of silanol $(-\mathrm{Si}-\mathrm{OH})$ groups on the surfaces, and in the presence of a third-generation SP, the surface hydroxyl of the silanol groups would form hydrogen bonds with the ether oxygen in the PEO side chains of the SP molecules, leading to PEO adsorption on the CSF surfaces and flocculation of the CSF particles. ${ }^{24}$ The PEO adsorption and flocculation might have hindered dense packing of the CSF particles and thereby substantially reduced the packing density.

The results in the second column of Table 3 indicate very clearly that double or triple blending of the cementitious materials could improve the packing density. For the double-blended mixes, the influence of blending is shown in Fig. 3 by plotting the packing density against the volume fraction of the finer material. For the double-blended OPC + CSF and PFA + CSF mixes, when a small amount of CSF was added, the packing density of the mix was significantly increased. For instance, when $30 \% \mathrm{CSF}$ was added to the OPC, the packing density was increased by $17 \%$ from 0.622 to 0.726 and when $15 \%$ CSF was added to the PFA, the packing density was increased by $16 \%$ from 0.646 to $0 \cdot 748$. Such significant increases in packing density may be attributed to the filling effect of the ultra-fine CSF particles. However, when more CSF was added, the packing density of the mix started to decrease because the CSF, which has a lower packing density, had become dominant. For the double-blended OPC + PFA mixes, the packing density of the mix increased slightly as more and more PFA was added. Since the OPC and the PFA have similar size distributions, the PFA had little filling effect when added to the OPC. 


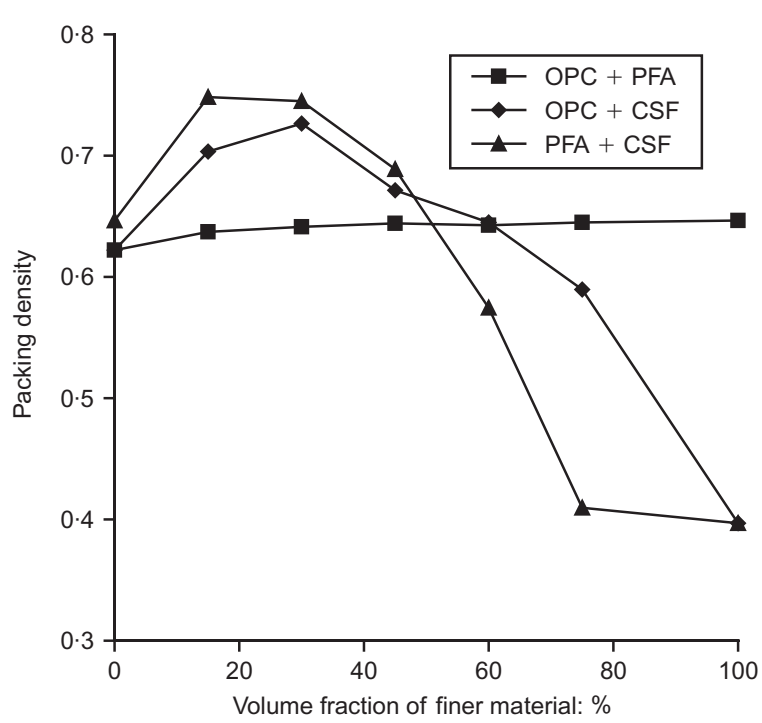

Fig. 3. Packing densities of double-blended mixes

The slight increase in packing density was attributable to the gradual replacement of the angular and less densely packed OPC particles with the spherical and more densely packed PFA particles.

For the triple-blended mixes, the influence of blending is shown in Fig. 4 by plotting the packing densities of the OPC + PFA + CSF mixes in the form of a ternary packing density diagram. From this diagram, it can be seen that by triple blending $25 \%$ OPC, $45 \%$ PFA and $30 \%$ CSF, the packing density could be increased to $0.752(21 \%$ higher than the packing density of pure OPC). In fact, there is a small region in the diagram near the lower right-hand corner with the packing density consistently higher than $0 \cdot 750$. Hence, by triple blending of OPC with both PFA and CSF to utilise the better particle shape of PFA and the filling effect of CSF, the packing density of the mix could be

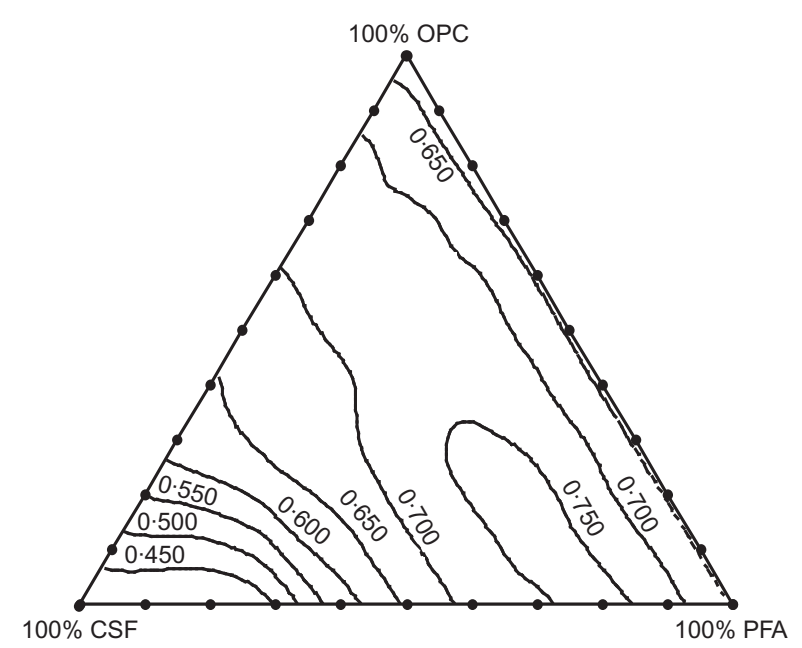

Fig. 4. Ternary packing density diagram of $O P C+P F A$ $+C S F$ increased to higher than possible with only double blending of OPC with either PFA or CSF. These results provide solid experimental evidence to verify the long-held postulation that blending different size cementitious materials together can improve the packing density.

\section{Predictions by packing models}

The predicted packing densities of the blended cementitious materials (mix No. 4 to 29) by the three packing models (models A, B and C) are tabulated in the third to eighth columns of Table 3 for comparison with the respective measured packing densities. When model A was applied to evaluate the predicted packing densities, in order to account for the effect of particle shape, the OPC, PFA and CSF were assigned sphericity values of $0 \cdot 792,1.000$ and $1 \cdot 000$, respectively. When model B was applied to evaluate the predicted packing densities, in order to incorporate the effect of compaction, different typical values of the compaction index $K$ were tried. It was found that a $K$-value of infinity (the value for the case of perfect compaction) would yield the closest agreement between the predicted and measured packing densities (this is in fact an indication of the high effectiveness of the proposed wet packing method in the mixing and packing of the cementitious materials). A $K$-value of infinity was therefore adopted when applying model B. Despite the apparent differences between the three packing models, the results presented in Table 3 clearly show that the three packing models actually yielded very similar predicted packing densities differing by not more than $6.5 \%$ in all the mixes studied.

Comparing the predicted packing densities to the measured packing densities, it can be seen that for the double-blended OPC + PFA mixes (mix No. 4 to 8 ), the predicted packing densities by all the three packing models agreed almost exactly with the corresponding measured packing densities, with maximum errors of only $1.4 \%, 1.6 \%$ and $1.7 \%$ when models A, B and C were applied, respectively. For the double-blended OPC + CSF mixes (mix No. 9 to 13), the differences between the predicted packing densities and the corresponding measured packing densities were somehow much larger; at a CSF content of $15 \%$, the differences were about $6 \%$ but as the CSF content increased to $75 \%$, the differences gradually increased to around $22 \%$. For the double-blended PFA + CSF mixes (mix No. 14 to 18), the differences between the predicted packing densities and the corresponding measured packing densities were also quite large, ranging from about $10 \%$ at a CSF content of $15 \%$ to slightly higher than $16 \%$ at higher CSF contents. For the triple-blended $\mathrm{OPC}+\mathrm{PFA}+\mathrm{CSF}$ mixes (mix No. 19 to 29), the predicted packing densities were all lower than the corresponding measured packing densities by significant differences, which were generally larger at higher CSF contents. The relatively small differences between 
the predicted and measured packing densities at low CSF content and the substantially larger differences between the predicted and measured packing densities at high CSF content indicated that something might have happened at high CSF content that had not been fully accounted for.

\section{Effect of lime on packing density of CSF}

The three mixes with the highest CSF contents are mix No. 3 containing $100 \%$ CSF, mix No. 13 containing $25 \% \mathrm{OPC}+75 \% \mathrm{CSF}$, and mix No. 18 containing $25 \%$ PFA $+75 \%$ CSF. They have measured packing densities of $0 \cdot 397,0 \cdot 590$ and $0 \cdot 410$, respectively. While pure CSF has a rather low packing density of 0.397 , the addition of $25 \%$ OPC dramatically increased the packing density by $49 \%$ to $0 \cdot 590$. Such increase in packing density was much larger than attributable to the occupying effect of the OPC particles. On the other hand, the addition of $25 \%$ PFA only increased the packing density by $3 \%$ to $0 \cdot 410$. As the OPC and PFA have similar size distributions and thus should have more or less the same occupying effects, the large difference in packing density between the mix with $25 \%$ OPC and the mix with $25 \%$ PFA revealed that the addition of OPC and the addition of PFA have different effects on the packing density, which could not be explained just from the physical packing point of view. Chemistry might have played a certain role causing the packing density of CSF to be changed when OPC or PFA was added.

One major chemical difference between OPC and PFA is that when OPC is mixed with water, it undergoes hydration and releases a substantial amount of lime as a by-product of hydration into the water whereas when PFA is mixed with water, only the small lime content in the PFA (usually a few per cent) is dissolved into the water. Hence, OPC and PFA would liberate different amounts of lime into the water. Since lime is alkaline, the $\mathrm{pH}$ of the water increases as lime goes into the water and the increase in $\mathrm{pH}$ should be larger with OPC added than with PFA added. According to Somasundaran and Zhang, ${ }^{24} \mathrm{pH}$ has a strong effect on the hydrolysis of silica and because of gradual dissociation of the silanol groups, both the adsorption density of PEO on CSF surfaces and the flocculation of CSF particles would decrease as the $\mathrm{pH}$ increases. The presence of lime and the increase in $\mathrm{pH}$ might have reduced the PEO adsorption and CSF flocculation, and consequently increased the packing density of the CSF.

To study the effect of lime on the packing density of pure CSF (mix No. 3), different amounts of lime (in the form of calcium hydroxide powders) were added to the water before mixing with the CSF and the resulting packing densities of the CSF measured. Four different amounts of lime, namely $0.74,7 \cdot 41,37.05$ and $74 \cdot 10$ $\mathrm{g} / 1$ (corresponding to $0.01,0.1,0.5$ and $1.0 \mathrm{~mole} / \mathrm{l}$, respectively), had been added to four separate samples of the CSF, each with the same amount of SP $(93.3 \mathrm{~kg} /$ $\mathrm{m}^{3}$ ) added. The resulting packing densities of the CSF were measured to be $0.461,0.479,0.520$ and 0.522 , respectively, as listed in Table 4 . These results showed that the presence of lime could improve the packing density of CSF by as much as $31 \%$. Basically, the packing density of CSF would increase steadily with the lime content and eventually reach a constant and maximum value at a sufficiently high lime content. Herein, the maximum packing density so achieved under the lime-sufficient condition of having a sufficiently high lime content is called lime sufficient packing density.

The packing densities of mix No. 13 containing 25\% OPC $+75 \%$ CSF, mix No. 16 containing 55\% PFA + $45 \%$ CSF, mix No. 17 containing 40\% PFA $+60 \%$ CSF and mix No. 18 containing 25\% PFA $+75 \%$ CSF were also measured again with different amounts of lime added. As before, different amounts of lime had been added to separate samples of each mix and the same amount of SP $\left(93 \cdot 3 \mathrm{~kg} / \mathrm{m}^{3}\right)$ was added to each sample. The measured packing densities at different lime contents are presented in Table 4. It is seen that for mix No. 13, the packing density was rather insensitive to the addition of lime, revealing that the lime liberated by the $25 \%$ OPC in the mix was already sufficient to avoid reduction in the packing density of CSF owing to lime deficiency. Among the other mixes, mix No. 16 was also insensitive to the addition of lime but both mix No. 17 and 18 had their packing densities significantly increased when lime was added. This revealed that without OPC, at least 55\% PFA would be needed to produce a lime-sufficient condition for avoiding reduction in the packing density of CSF. Nevertheless, in practice, since the OPC content in the mix is unlikely

Table 4. Measured packing densities of mixes containing CSF in the presence of lime

\begin{tabular}{|c|c|c|c|c|c|c|c|c|}
\hline \multirow[t]{2}{*}{ Mix No. } & \multicolumn{3}{|c|}{ Mix proportions: $\%$ by volume } & \multicolumn{5}{|c|}{ Amount of lime added to the mixing water: $g / 1$} \\
\hline & OPC & PFA & CSF & 0 & 0.74 & $7 \cdot 41$ & $37 \cdot 05$ & $74 \cdot 10$ \\
\hline 3 & 0 & 0 & 100 & $0 \cdot 397$ & $0 \cdot 461$ & 0.479 & $0 \cdot 520$ & 0.522 \\
\hline 13 & 25 & 0 & 75 & $0 \cdot 590$ & $0 \cdot 594$ & $0 \cdot 593$ & - & - \\
\hline 16 & 0 & 55 & 45 & $0 \cdot 689$ & $0 \cdot 681$ & 0.683 & - & - \\
\hline 17 & 0 & 40 & 60 & $0 \cdot 575$ & $0 \cdot 589$ & 0.625 & 0.631 & - \\
\hline 18 & 0 & 25 & 75 & $0 \cdot 410$ & $0 \cdot 457$ & $0 \cdot 576$ & $0 \cdot 580$ & - \\
\hline
\end{tabular}


to be lower than $25 \%$ by volume, there should be no lime deficiency problem that would reduce the packing density of CSF.

\section{Predictions by packing models with effect of lime accounted for}

From the above, the lime-sufficient packing densities of mix No. 3, 13, 16, 17 and 18 (taken as the respective maximum packing densities within the ranges of lime contents tested) were obtained as $0.522,0.594,0.689$, 0.631 and 0.580 , respectively. To take into account the effect of lime, for pure CSF, the original packing density of 0.397 was replaced by the lime-sufficient packing density of 0.522 as input parameter entered into the packing models for more realistic predictions of the packing densities of the various mixes which were mostly under lime-sufficient condition. Furthermore, for mix No. 13, 16, 17 and 18, which might have their packing densities afflicted by lime deficiency, their measured packing densities were replaced by their respective lime-sufficient packing densities so that direct comparison with the predictions by the packing models based on lime-sufficient condition could be made. Table 5 presents the measured and predicted packing densities of the various mixes after the above changes.

From the comparison in Table 5, it can be seen that with the effect of lime accounted for, the predicted packing densities by the three packing models agreed very closely with the measured packing densities by the proposed wet packing method. In general, the differences between the predicted and measured packing densities were well within several per cent and on a par with the expected experimental errors in the packing density measurements. More importantly, the differences no longer increased with the CSF content. For evaluating the accuracies of the three packing models, the average differences between the predicted and measured packing densities have been calculated as $-0.6 \%,-1 \cdot 2 \%$ and $-2 \cdot 5 \%$, and the average absolute differences between the predicted and measured packing densities have been calculated as $1 \cdot 6 \%, 2 \cdot 3 \%$ and $2.9 \%$, for models A, B and C, respectively. Although model A appeared to be the most accurate, all the packing models should be acceptable for practical engineering applications. The good agreement between the predicted and measured results also verified the validity and accuracy of the proposed wet packing method.

\section{Conclusions}

A new wet packing method for measuring the packing density of cementitious materials in a paste has

Table 5. Comparison between measured results and predictions by packing models with effect of lime accounted for

\begin{tabular}{|c|c|c|c|c|c|c|c|}
\hline \multirow[t]{2}{*}{ Mix No. } & \multirow{2}{*}{$\begin{array}{c}\text { Measured } \\
\text { packing density }\end{array}$} & \multicolumn{2}{|c|}{ Model A } & \multicolumn{2}{|c|}{ Model B } & \multicolumn{2}{|c|}{ Model C } \\
\hline & & $\begin{array}{c}\text { Predicted } \\
\text { packing density }\end{array}$ & Difference: \% & $\begin{array}{c}\text { Predicted } \\
\text { packing density }\end{array}$ & Difference: \% & $\begin{array}{c}\text { Predicted } \\
\text { packing density }\end{array}$ & Difference: $\%$ \\
\hline 4 & 0.637 & 0.628 & $-1 \cdot 4$ & 0.627 & $-1 \cdot 6$ & 0.626 & -1.7 \\
\hline 5 & $0 \cdot 641$ & 0.633 & $-1 \cdot 2$ & 0.632 & $-1 \cdot 4$ & 0.631 & $-1 \cdot 6$ \\
\hline 6 & $0 \cdot 644$ & 0.637 & $-1 \cdot 1$ & 0.636 & $-1 \cdot 2$ & 0.635 & $-1 \cdot 4$ \\
\hline 7 & $0 \cdot 643$ & $0 \cdot 640$ & -0.5 & $0 \cdot 640$ & -0.5 & 0.639 & -0.6 \\
\hline 8 & $0 \cdot 645$ & 0.643 & $-0 \cdot 3$ & $0 \cdot 643$ & $-0 \cdot 3$ & 0.643 & $-0 \cdot 3$ \\
\hline 9 & 0.703 & 0.699 & -0.6 & 0.678 & $-3 \cdot 6$ & 0.680 & $-3 \cdot 3$ \\
\hline 10 & 0.726 & 0.749 & $+3 \cdot 2$ & 0.743 & $+2 \cdot 3$ & 0.703 & $-3 \cdot 2$ \\
\hline 11 & 0.671 & 0.685 & $+2 \cdot 1$ & 0.688 & $+2 \cdot 5$ & 0.683 & $+1 \cdot 8$ \\
\hline 12 & $0 \cdot 645$ & 0.632 & $-2 \cdot 0$ & 0.634 & $-1 \cdot 7$ & 0.635 & $-1 \cdot 6$ \\
\hline 13 & 0.594 & $0 \cdot 586$ & $-1 \cdot 3$ & 0.587 & $-1 \cdot 2$ & 0.589 & $-0 \cdot 8$ \\
\hline 14 & 0.748 & 0.719 & $-3 \cdot 9$ & 0.695 & $-7 \cdot 1$ & 0.692 & $-7 \cdot 5$ \\
\hline 15 & 0.745 & 0.747 & $+0 \cdot 3$ & 0.748 & $+0 \cdot 4$ & 0.704 & $-5 \cdot 5$ \\
\hline 16 & 0.689 & 0.684 & -0.7 & 0.687 & $-0 \cdot 3$ & 0.681 & $-1 \cdot 2$ \\
\hline 17 & 0.631 & 0.631 & $+0 \cdot 0$ & 0.633 & $+0 \cdot 3$ & 0.634 & $+0 \cdot 5$ \\
\hline 18 & $0 \cdot 580$ & $0 \cdot 586$ & $+1 \cdot 0$ & $0 \cdot 587$ & $+1 \cdot 2$ & $0 \cdot 589$ & $+1 \cdot 6$ \\
\hline 19 & $0 \cdot 718$ & $0 \cdot 705$ & $-1 \cdot 8$ & 0.683 & $-4 \cdot 9$ & 0.681 & $-5 \cdot 2$ \\
\hline 20 & 0.731 & $0 \cdot 710$ & $-2 \cdot 9$ & 0.687 & $-6 \cdot 0$ & 0.690 & $-5 \cdot 6$ \\
\hline 21 & 0.730 & 0.714 & $-2 \cdot 2$ & 0.691 & $-5 \cdot 3$ & 0.703 & $-3 \cdot 7$ \\
\hline 22 & $0 \cdot 742$ & $0 \cdot 716$ & $-3 \cdot 5$ & 0.693 & $-6 \cdot 6$ & 0.704 & $-5 \cdot 1$ \\
\hline 23 & 0.736 & 0.748 & $+1 \cdot 6$ & 0.746 & $+1 \cdot 4$ & 0.697 & $-5 \cdot 3$ \\
\hline 24 & 0.735 & 0.748 & $+1 \cdot 8$ & 0.748 & $+1 \cdot 8$ & 0.701 & $-4 \cdot 6$ \\
\hline 25 & 0.752 & 0.748 & -0.5 & 0.748 & -0.5 & 0.704 & $-6 \cdot 4$ \\
\hline 26 & 0.665 & 0.685 & $+3 \cdot 0$ & 0.688 & $+3 \cdot 5$ & 0.676 & $+1 \cdot 7$ \\
\hline 27 & 0.691 & 0.685 & -0.9 & 0.688 & $-0 \cdot 4$ & 0.678 & -1.9 \\
\hline 28 & $0 \cdot 700$ & 0.685 & $-2 \cdot 1$ & 0.687 & -1.9 & 0.680 & $-2 \cdot 9$ \\
\hline 29 & 0.639 & 0.632 & $-1 \cdot 1$ & 0.634 & -0.8 & 0.633 & -0.9 \\
\hline
\end{tabular}


been developed and successfully applied to nonblended, double-blended and triple-blended mixes containing different proportions of OPC, PFA and CSF. From the packing density results of the non-blended mixes, it was found that, although the OPC and PFA have similar particle size distributions, owing to the better spherical shape of the PFA particles, the PFA has a higher packing density than the OPC. However, although the CSF particles are also spherical in shape, the CSF turned out to have the lowest packing density. This may be attributed to PEO adsorption on the CSF surfaces and flocculation of the CSF particles arising from hydrogen bonding between the silanol groups on the CSF surfaces and the PEO side chains of the thirdgeneration SP added. On the other hand, the packing density results of the blended mixes provide solid evidence to verify the long-held postulation that double and even triple blending of different size cementitious materials together can significantly improve the packing density. A maximum packing density of 0.752 has been achieved by blending $25 \%$ OPC $+45 \%$ PFA + $30 \%$ CSF.

The three packing models developed by Yu et al., ${ }^{17}$ DeLarrard $^{11}$ and Dewar ${ }^{12}$ have been employed to predict the packing densities of the mixes tested and the predicted packing densities so obtained were compared to the corresponding measured packing densities. It was found that although acceptable agreement between the predicted and measured packing densities has been achieved at low CSF content, there were substantial errors at high CSF content. In order to resolve this problem, additional tests were carried out to measure the packing densities of pure CSF and several other mixes with different amounts of lime added. It was discovered that the packing density of CSF was highly dependent on the lime content and that the low packing densities of pure CSF and other mixes with high CSF contents were attributable to lime deficiency (not having sufficient lime to avoid reduction in the packing density of CSF owing to PEO adsorption and CSF flocculation). Nevertheless, with at least $25 \%$ OPC or $55 \%$ PFA added, the OPC or PFA would liberate sufficient lime into the water to alleviate such lime deficiency.

To account for the effect of lime, the lime-sufficient packing density of CSF was input into the packing models to evaluate the predicted packing densities of the various mixes tested and the measured packing densities of the mixes afflicted by lime deficiency were replaced by their respective lime-sufficient packing densities. After these changes, the predicted packing densities by the three packing models agreed with the measured packing densities by the proposed wet packing method to within an average absolute difference of only $3 \%$. Such good agreement verified the applicability of all the three packing models to cementitious materials (provided of course the effect of lime has been accounted for) and the validity and accuracy of the proposed wet packing method.

\section{Acknowledgement}

The work described in the current paper was fully supported by a grant from the Research Grants Council of the Hong Kong Special Administrative Region, China (Project No. HKU 7139/05E).

\section{References}

1. Reed J. S. Principles of Ceramics Processing, 2nd edn. Wiley, New York, USA, 1995.

2. FAyed M. E. and Otten L. (eds) Handbook of Powder Science and Technology, 2nd edn. Chapman \& Hall, New York, USA, 1997.

3. Powers T. C. The Properties of Fresh Concrete. Wiley, New York, USA, 1968.

4. British Standards Institution. Testing of Aggregates, Part 2: 1995 Method of Determination of Density. BSI, UK, 1995 , BS 812 .

5. American Society for Testing And Materials. Standard Test Method for Bulk Density ('Unit Weight') and Voids in Aggregate. ASTM, West Conshohocken, PA, 2003, ASTM C 29/C 29M-97.

6. Goltermann P., Johansen V. and PalbøL L. Packing of aggregates: an alternative tool to determine the optimal aggregate mix. ACI Materials Journal, 1997, 94, No. 5, 435-443.

7. Lange F., Mörtel H. and Rudert V. Dense packing of cement pastes and resulting consequences on mortar properties. Cement and Concrete Research, 1997, 27, No. 10, 1481-1488.

8. KWAN A. K. H. Use of condensed silica fume for making highstrength, self-consolidating concrete. Canadian Journal of Civil Engineering, 2000, 27, No. 4, 620-627.

9. XIE Y. J., LiU B. J., Yin J. and Zhou S. Q. Optimum mix parameters of high-strength self-compacting concrete with ultrapulverized fly ash. Cement and Concrete Research, 2002, 32, No. 3, 477-480.

10. Yu A. B., Bridgwater J. and Burbidge A. On the modelling of the packing of fine particles. Powder Technology, 1997, 92, No. 3, 185-194.

11. Delarrard F. Concrete Mixture Proportioning: A Scientific Approach. E\&FN Spon, London, UK, 1999.

12. Dewar J. D. Computer Modelling of Concrete Mixtures. E\&FN Spon, London, UK, 1999.

13. British Standards Institution. Methods of Testing Cement Part 3: 1995 Determination of Setting Time and Soundness. BSI, London, 1995, BS EN 196.

14. Westman A. E. R. and Hugill H. R. The packing of particles. Journal of American Ceramic Society, 1930, 13, No. 10, 767779.

15. Stovall T., Delarrard F. and Buil M. Linear packing density model of grain mixtures. Powder Technology, 1986, 48, No. 1, $1-12$.

16. YU A. B. and Standish N. Porosity calculations of multicomponent mixtures of spherical particles. Powder Technology, 1987, 52, No. 3, 233-241.

17. Yu A. B., Zou R. P. and Standish N. Modifying the linear packing model for predicting the porosity of nonspherical particle mixtures. Industrial and Engineering Chemistry Research, 1996, 35, No. 10, 3730-3741.

18. British Standards Institution. Cement Part 1: 2000 Composition, Specifications and Conformity Criteria for Common Cements. BSI, London, 2000, BS EN 197.

19. British Standards Institution. Pulverized-Fuel Ash Part 1: 1997 Specification for Pulverized-Fuel Ash for Use with Portland Cement. BSI, London, 1997, BS 3892.

20. American Society for Testing and Materials. Standard Specification for Silica Fume Used in Cementitious Mixtures. ASTM, West Conshohocken, PA, 2005, ASTM C 1240-05.

Magazine of Concrete Research, 2008, 60, No. 3 
21. British Standards Institution. Determination of the Specific Surface Area of Powders Part 2: 1982 Recommended Air Permeability Methods. BSI, London, 1982, BS 4359.

22. Kwan A. K. H. and Mora C. F. Effects of various shape parameters on packing of aggregate particles. Magazine of Concrete Research, 2001, 53, No. 2, 91-100.

23. Sakai E., Yamada K. and Ohta A. Molecular structure and dispersion-adsorption mechanisms of comb-type superplasticizers used in Japan. Journal of Advanced Concrete Technology, 2003, 1, No. 1, 16-25.
24. Somasundaran P. and Zhang L. Modification of silica-water interfacial behavior by adsorption of surfactants, polymers, and their mixtures. In Surfactant Science Series Volume 90: Adsorption on Silica Surfaces (PAPIRER E. (ed.)). Marcel Dekker, New York, USA, 2000, ch. 14, pp. 441-462.

Discussion contributions on this paper should reach the editor by 1 October 2008 